\title{
Desenvolvimento de descascador de legumes ergonômico voltado a usuários com restrição visual
}

\author{
Development of ergonomic vegetable peeler to visually impaired users
}

\author{
VEDAN, Alexssander Felipe \\ UNESP, Bachelor Student, alexssander.vedan@unesp.br \\ JUNIOR, João Carlos Scheffer \\ UNESP, Bachelor Student, joaocscheffer@gmail.com \\ MEDOLA, Fausto Orsi \\ UNESP, Professor Titular, fausto.medola@unesp.br \\ PASCHOARELLI, Luis Carlos \\ UNESP, Professor Titular, luis.paschoarelli@unesp.br
}

\section{RESUMO}

O descascador de legumes é um objeto amplamente utilizado e está presente em grande parte das cozinhas. A prática de descascar demanda destreza por parte do usuário, porém, uma vez que o usuário possui deficiência visual essa tarefa tem um elevado nível de complexidade devido a dificuldade em identificar corretamente a posição do objeto e sua forma de utilização. Este artigo descreve 0 desenvolvimento do redesenho de dois descascadores de legumes, bem como a avaliação ergonômica com uso de um protótipo, os quais atendia as demandas de inovação, ergonomia e inclusão. As etapas de desenvolvimento estão divididas em: aplicação de testes ergonômicos e de usabilidade com dois descascadores convencionais, definição de diretrizes de projeto, desenvolvimento do projeto, produção do protótipo e revisão do projeto com base na avaliação dos usuários. O protótipo produzido foi bem avaliado nos testes de usabilidade aplicados, mostrando-se mais bem aceito entre os participantes não videntes, desta forma o protótipo atingiu seus objetivos propostos nos fatores ergonomia e funcionalidade para 0 público alvo.

Ergonomia; Design de produto; Design inclusivo; Usabilidade

\section{ABSTRACT}

The vegetable peeler is a widely used object and is present in most kitchens. The action of peeling demands dexterity by the user, however, since the user with visual impairment this task has a high level of complexity 


\section{$17^{\circ}$ ERGODESIGN}

\& USIHC 2019

PUC-Rio, 11 a 13 de dezembro

Rio de Janeiro, RJ, Brasil $17^{\circ}$ Ergodesign - Congresso Internacional de Ergonomia e Usabilidade de Interfaces Humano Tecnológica: Produto, Informações Ambientes Construídos e Transporte

$17^{\circ}$ USIHC - Congresso Internacional de Ergonomia e Usabilidade de Interfaces Humano Computador

due to the difficulty in correctly identifying the position of the object and its use. This paper describes the development of two vegetable peelers redesign, as well as the ergonomic evaluation using a prototype, which met the demands of innovation, ergonomics and inclusion. The development stages were divided into application of ergonomic and usability tests with two conventional peelers, definition of design guidelines, project development, prototype production and design review based on user evaluation. The prototype produced was well evaluated in the usability tests applied, being better accepted among visually-impaired participants, thus the prototype reached its objectives in the ergonomics and functionality factors for the target audience.

Ergonomics; Product design; Inclusive design; usability

\section{INTRODUÇÃO}

O descascador de legumes é um objeto amplamente utilizado em atividades de preparo de alimentos e está presente em grande parte das cozinhas, especialmente nos últimos anos em que "cozinhar" caiu no gosto da população em geral. Os modelos mais populares de descascador já possuem um formato consolidado na indústria, sendo geralmente pequenos e finos, limitando a escolha do formato mais adequado a necessidade do usuário, entretanto, o uso desses modelos podem conduzir seus usuários à adquirirem lesões músculo-esqueléticas. Dentre elas, podemos citar aquelas ocasionadas por movimentos repetitivos, causando uma incapacidade não apenas na atividade ocupacional, mas também na qualidade de vida do indivíduo como um todo (CARVALHO, 2018). Dessa forma faz-se necessário o desenvolvimento de utensílios que favorecem o manejo pelo usuário, minimizando os danos a sua musculatura.

Para que um objeto, equipamento, dispositivo e/ou ferramentas manuais sejam considerados úteis, inúmeros fatores são considerados, dentre eles destaca-se a ergonomia, que garante que o processo de design seja consistente com o modelo de interação do usuário, levando em consideração as características de seus usuários, abrangendo aspectos como força, tamanho, peso, gênero e questões cognitivas e o próprio design ou processo de projeto, especialmente quando considerado como elemento de qualidade do produto nestas relações

(PASCHOARELLI, 2000; AGNER; MORAES, 2018).

De acordo com Santos et al. (2019), ao compreender a importância da interação do usuário com o produto, o designer deve buscar métodos para coletar as informações necessárias para nortear o projeto e dessa forma, incorporar ao produto as reais necessidades e desejos dos consumidores, uma vez que a usabilidade de um produto possui ligação direta com a percepção de conforto, o que não depende apenas do produto e de seus elementos em si, mas também da percepção do próprio indivíduo.

Desta forma, pode-se afirmar que a percepção de um produto de uso doméstico varia de acordo com usuário, da sua experiência com o uso desse objeto e de estado físico e cognitivo (SANTOS et al., 2019). Logo, é possível fazer uso da Ergonomia Participativa como o método pelo qual os usuários finais do produto desempenham um papel ativo na identificação e na análise dos problemas ergonômicos, assim como na formulação e implementação de suas soluções, o que requer do usuário utilização efetiva desse objeto para atingir seus objetivos de forma satisfatória (IIDA, 2005; IIDA, 2016).

No caso do redesenho do descascador de legumes, que é um produto já existente, o desenvolvimento aconteceria através do Projeto Participativo, no qual o usuário é envolvido desde a etapa inicial. Desde o início o projeto é focalizado no usuário e na tarefa. Dessa forma, os usuários fazem avaliações contínuas a cada etapa do projeto. Assim, os eventuais erros ou desvios do projeto são corrigidos antes de se chegar ao protótipo (IIDA, 2005). 
Outra demanda para o Design de produtos de uso cotidiano refere-se à necessidade cada vez maior de projetos que atendam pessoas com características específicas, de modo a promover qualidade de vida a todos, para que independentemente de suas necessidades, características, fatores como envelhecimento ou necessidades especiais, possam ser beneficiadas por essas propostas (MELO, 2006; PEREIRA; SANTOS, 2019).

Assim, a elaboração desse estudo ocorreu de maneira a atender de forma mais inclusiva pessoas com deficiência visual. A prática de descascar legumes pode parecer simples, mas demanda atenção e destreza por parte do usuário. Quando existe uma dificuldade ou completa restrição visual, essa tarefa tem o nível de complexidade elevado, visto a necessidade de precisão no movimento, e o risco que uma lâmina cortante pode trazer a esse indivíduo. Por tanto a metodologia desenvolvida visou reduzir os riscos e facilitar seu uso não só para a população estudada como também para a população em geral.

Buscando atender as necessidades desse público específico, bem como contemplar a população geral, propôs-se desenvolver um novo modelo de descascador que considera principalmente os conceitos ergonômicos de usabilidade e inovação. O redesenho do produto teve como foco uma forma inovadora e natural de encaixe na mão do usuário, que trouxesse não só segurança, eficiência e conforto, mas também um design sofisticado e atrativo. O presente artigo teve como objetivo demonstrar o desenvolvimento deste novo modelo de descascador. O estudo resultou em um painel para apresentação do processo de desenvolvimento do protótipo e, principalmente, dos testes de usabilidade e suas respectivas análises; relatórios sobre os procedimentos metodológicos e produtivos, modelagens virtuais e renders; projeto executivo do produto e; um protótipo físico.

\section{PROCEDIMENTOS METODOLÓGICOS}

Os procedimentos metodológicos realizados no decorrer do desenvolvimento do projeto se dividiram em: aplicação de testes de ergonomia e usabilidade com dois descascadores convencionais; Diretrizes iniciais de projeto; Desenvolvimento de projeto e; Produção do protótipo.

\subsection{Aplicação de testes de ergonomia e usabilidade com dois descascadores convencionais} Foram realizados testes de usabilidade no Laboratório de Ergonomia e Interfaces (LEI) da UNESP Bauru de dois tipos de descascadores comercialmente disponíveis, identificados ao longo deste trabalho como "tipo Y" e "tipo Faca" (Figura 1). Através desses testes foi possível avaliar vários pontos negativos e positivos de ambos modelos, que representam grande parte dos variados tipos de descascadores que há no mercado.

Figura 1: Descascadores comercialmente disponíveis Fonte: dos autores (permissão de uso)

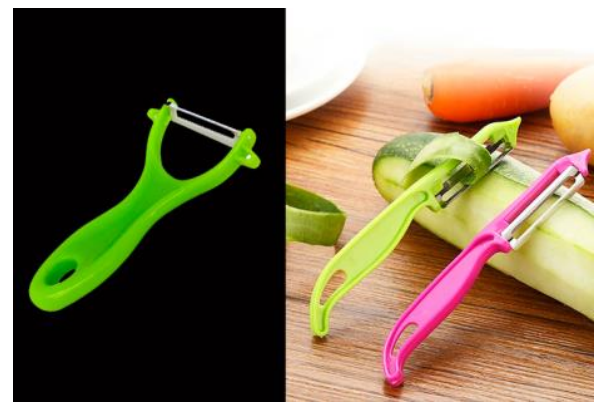




\section{$17^{\circ}$ ERGODESIGN}

\& USIHC 2019

PUC-Rio, 11 a 13 de dezembro

Rio de Janeiro, RJ, Brasil $17^{\circ}$ Ergodesign - Congresso Internacional de Ergonomia e Usabilidade de Interfaces Humano Tecnológica: Produto, Informações Ambientes Construídos e Transporte

$17^{\circ}$ USIHC - Congresso Internacional de Ergonomia e Usabilidade de Interfaces Humano Computador

O teste foi aplicado em três categorias de grupos: sem restrição, com restrição parcial e restrição total da visão. Para os grupos de restrição parcial e total, foram utilizados óculos com tratamento das lentes com efeito de embaçamento, e com oclusão total das lentes, respectivamente. Desse modo, foi possível avaliar o nível de funcionalidade oferecida por cada tipo de descascador e qual o modelo pode ser considerado mais ou menos inclusivo quando se trata de usuários com deficiências visuais. A atividade foi dividida em duas etapas: primeiramente os alunos tiveram que realizar a tarefa de descascar um pepino usando os modelos de descascador encontrados no mercado, e em seguida, responder a dois questionários referentes à experiência quanto à ergonomia, usabilidade e estética do descascador.

Os testes foram feitos com duas metodologias diferentes, sendo que a primeira se baseava em uma lista com dez assertivas acerca da experiência de uso que o usuário deveria apontar o seu nível de concordância com as afirmações. Chamado de SUS (System Usability Scale), este tipo de teste cada posição de concordância ou discordância valia uma pontuação de 1 a 5 , sendo 1 o "discordo totalmente" e o 5 o "concordo totalmente". O cálculo da pontuação também muda de acordo com o tipo de pergunta, se for uma afirmação positiva sobre o produto, o cálculo deve ser feito com a fórmula "posição-1", logo, se o usuário concordar totalmente com a assertiva (posição que vale 5), então essa resposta dará 4 pontos ao produto, que é o máximo que uma questão positiva pode valer. Se a assertiva for negativa, a fórmula se altera para " 5 - posição", então, se o usuário discordar totalmente da afirmação (posição que vale 1), essa resposta também dará 4 pontos ao produto. Por exemplo, se o produto testado for excelente e o usuário concordar com todas as afirmativas positivas e discordar de todas as afirmativas negativas, a soma dos resultados dará 40. Mas para obter a pontuação geral do SUS, esse valor deve ser multiplicado por 2,5. No exemplo dado, a pontuação geral seria $40 * 2,5=100$.

O segundo teste foi o DS (Diferencial Semântico). Nele, são colocados dez pares de adjetivos antagônicos separados por uma escala de sete pontos, e o usuário deve indicar a qual dos adjetivos aquele produto mais se aproxima. A pontuação varia de 1 a 10, e o resultado final é a soma de todas as médias de todos os pares de adjetivos. Cada um dos adjetivos recebe uma classificação entre positivo e negativo, e elas devem ser escolhidas antes da aplicação do teste. Para ilustrar, neste teste o par caro/barato, tem como elemento positivo o "barato" e negativo o "caro", e o objetivo do teste é que o produto seja percebido com mais características positivas possíveis, pois assim sua pontuação final irá aumentar. Por exemplo, se um dos pares de adjetivos é "higiênico - antihigiênico", sendo que o caráter positivo é o de higiênico, e o negativo é o de anti-higiênico, e a percepção do usuário é de que aquele produto é muito higiênico, então a pontuação para esse par será com números altos. Ao final de todos os sujeitos testarem, é feita uma média com os valores atribuídos a cada par. E, ao final, todas as médias para os dez pares são tomadas para chegar ao número final.

Como pode ser visto na Figura 2, os testes com grupo vidente, parcialmente vidente e cego aplicados ao descascador "Tipo Y" obtiveram 71.75, 62.25 e 67.78 pontos e o descascador "Tipo faca" 55, 47.5 e 34.17 no método SUS, respectivamente. Já para o teste de DS, os resultados com descascador tipo $Y$ foram: 44.3, 43.9 e 43.56, e o do tipo Faca 38.1, 34 e 29,89, sendo vidente, parcialmente vidente e cego respectivamente. 
Figura 2: Análise Diferencial Semântico descascadores convencionais

Fonte: dos autores (permissão de uso)
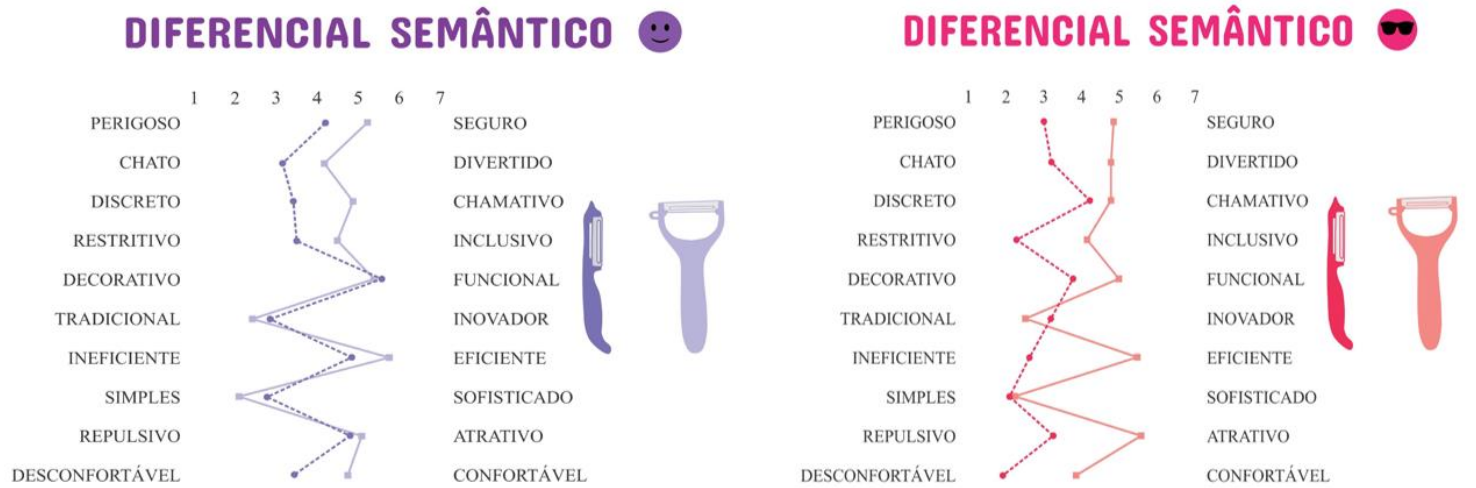

Figura 3: Análise SUS descascadores convencionais

Fonte: dos autores (permissão de uso)

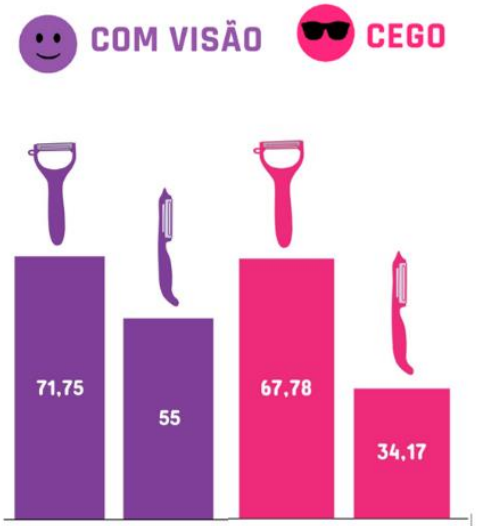

Pelo teste SUS, baseado nas perguntas, o descascador tipo Faca atingiu o desempenho mais inferior nas questões que envolviam a facilidade da pega e a qualidade do material utilizado no produto. O resultado do teste DS (diferencial semântico) mostrou que o descascador foi percebido pelos usuários videntes como "tradicional" e "simples".

Ao comparar o grupo não vidente em relação aos demais, verificou-se que há uma diferença muito maior entre os dois tipos naquele grupo, levando à conclusão de que o tipo $\mathrm{Y}$ é mais inclusivo que o tipo faca.

Pode-se notar, também, que a lâmina, quando paralela ao cabo, traz malefícios como insegurança, desconforto, exclusão e ineficiência à usuários deficientes. Porém, o descascador com a lâmina transversal ao cabo também precisava de inovações que aperfeiçoasse sua eficiência.

Os testes com o descascador $Y$ e Faca foram cronometrados, nos testes com pessoas videntes e com visão parcial, os tempos foram próximos, mas os testes com pessoas sem o uso da visão o tempo para concluir a tarefa dobrou, e podemos concluir com esses dados que, para pessoas sem visão, o tipo de descascador utilizado não afetou o tempo gasto para concluir a tarefa. 
Figura 4. Média de tempo descascadores comuns

Fonte: dos autores (permissão de uso)

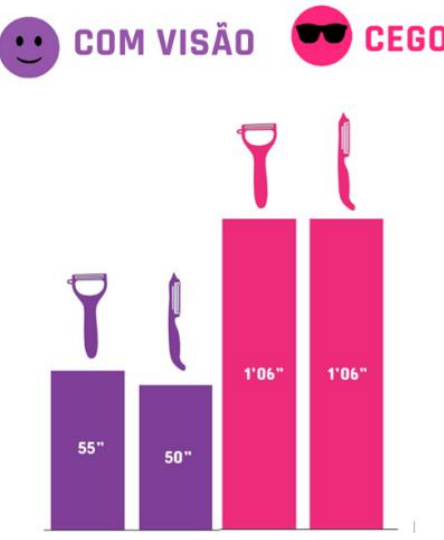

\subsection{Diretrizes de projeto}

A etapa de definição de diretrizes do projeto foi composta pelo briefing, apresentado inicialmente pela disciplina, o qual definia-se pelo redesenho levando em consideração usuário videntes, parcialmente videntes e cego dos descascadores apresentados durante a aula (modelo tipo Y e modelo tipo Faca). Para definição e afunilamento do problema, foi realizado um brainstorm sobre a problemática, os resultados dos testes e a definição esquemática das diretrizes para o projeto. Os principais pontos destacados foram:

- Evitar o contato do dedo com a lâmina;

- Formato que permita o apoio palmar completo para melhor aderência e controle (aumento da sensação de segurança e acurácia no descascamento);

- Fácil identificação da maneira de uso, visualmente e pelo tato e;

- Uso adequado para destros e canhotos.

A equipe focou, então, na conceituação que seria aplicada ao projeto, que pode ser ilustrada na figura 5. A conceituação foi essencial para definir uma forma que transmitisse firmeza na pega e no ato de descascar para que pudesse fornecer, desta forma, melhor segurança e conforto ao usuário. O ponto de partida foi a forma geométrica de uma esfera, para que o protótipo pudesse ser manipulado de várias formas diferentes, possibilitando distintas posições de pegas aos usuários.

Figura 5. Conceituação

Fonte: dos autores (permissão de uso)
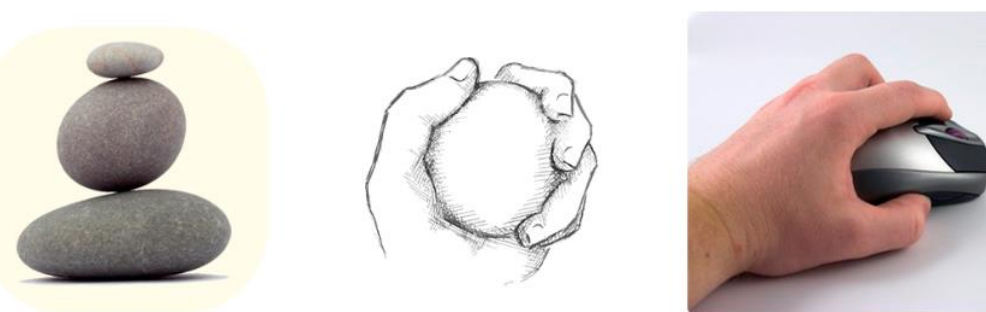


\subsection{Desenvolvimento de projeto}

A equipe fez estudo de projetos similares que fossem diferentes de descascadores comuns, principalmente nas pegas, priorizando produtos com formas mais orgânicas e ergonômicas. A etapa de pesquisa de similares teve como objetivo conhecer melhor os modelos de descascadores disponíveis no mercado para, assim, ser possível listar suas principais características, como tamanho e formato. Com os descascadores encontrado, foi possível extrair características que pudessem auxiliar a criação de algo novo, ergonômico e com melhorias estéticas. Alguns desses itens podem ser vistos nas figuras 6 e 7 .

Figura 6. Descascador similar Ease

Fonte: www.behance.net/gallery/31258933/ID-2-Ease-e-Peeler

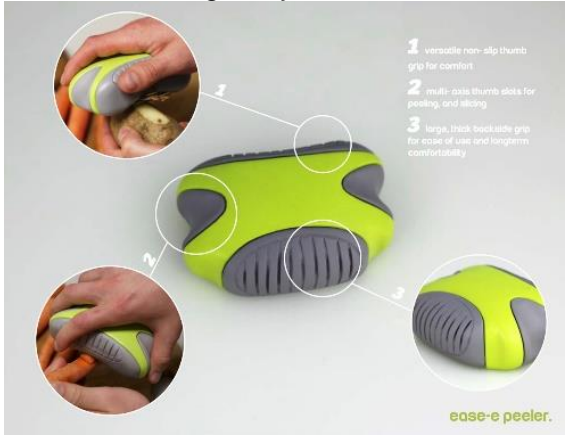

Figura 7. Descascador similar Potato Fonte: www.behance.net/gallery/24769783/Potato-Peeler
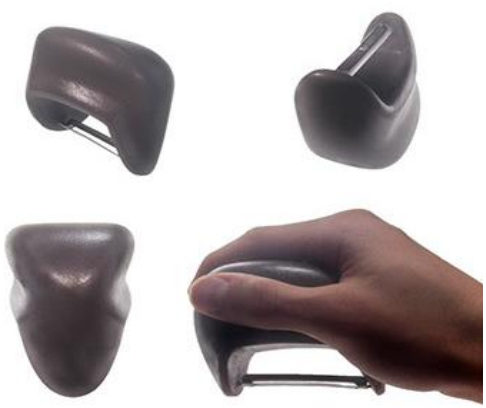

Com a conceituação e pesquisa de similares concluída, cada integrante foi responsável pela elaboração de modelos de papelão para discussão da forma (Figura 8). Posteriormente, foram definidos dois modelos de base (2 e 3) que combinados nortearam a forma final (Figura 10). A análise dos modelos feitos rusticamente em papelão foi essencial para definir uma forma que seria o ponto de partida. 


\section{$17^{\circ}$ ERGODESIGN}

\& USIHC 2019

PUC-Rio, 11 a 13 de dezembro

Rio de Janeiro, RJ, Brasil $17^{\circ}$ Ergodesign - Congresso Internacional de Ergonomia e Usabilidade de Interfaces Humano Tecnológica: Produto, Informações Ambientes Construídos e Transporte

$17^{\circ}$ USIHC - Congresso Internacional de Ergonomia e Usabilidade

de Interfaces Humano Computador

Figura 8. Modelos iniciais

Fonte: dos autores (permissão de uso)

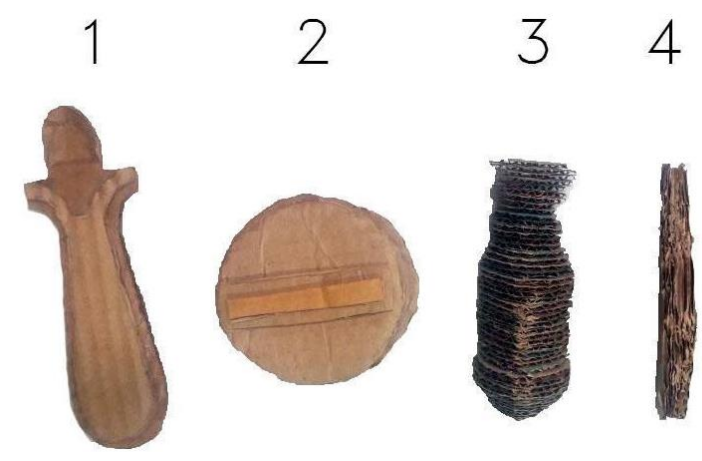

Com formato esférico, o modelo 2 em papelão apresentava um formato diferenciado dentre os descascadores já existentes no mercado. Já o formato do modelo 3 apresentou bom desenvolvimento ergonômico na pega, garantindo conforto ao usuário. Para unir as principais características desses dois modelos, foram realizados sketches para conciliar melhora ergonômica com a melhora estética e funcional prevista, como pode ser visto na figura $9 \mathrm{e}$ figura 10.

Figura 9. Sketches iniciais

Fonte: dos autores (permissão de uso)

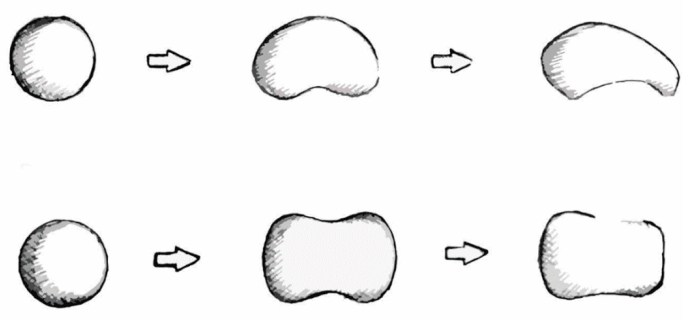

Figura 10. Sketches iniciais

Fonte: dos autores (permissão de uso)

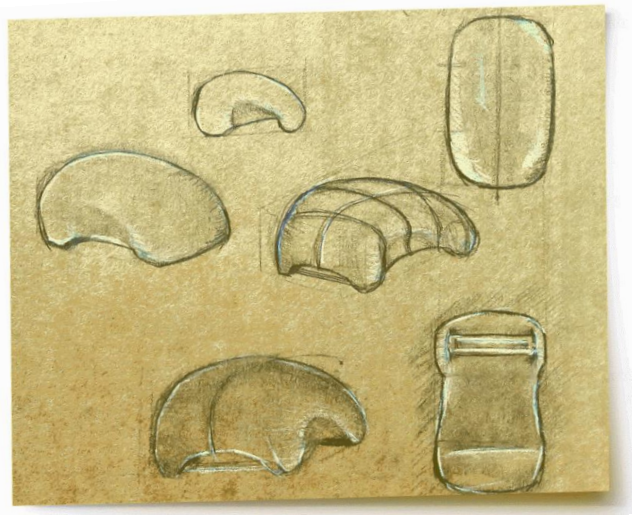




\section{$17^{\circ}$ ERGODESIGN}

\section{\& USIHC 2019}

PUC-Rio, 11 a 13 de dezembro

Rio de Janeiro, RJ, Brasil $17^{\circ}$ Ergodesign - Congresso Internacional de Ergonomia e Usabilidade de Interfaces Humano Tecnológica: Produto, Informações Ambientes Construídos e Transporte

$17^{\circ}$ USIHC - Congresso Internacional de Ergonomia e Usabilidade

de Interfaces Humano Computador

A etapa de sketches sucedeu na modelagem em materiais que permitem mais detalhamento da forma. Os modelos foram feitos em argila (clay) e PU (poliuretano expandido) como mostra a figura 11 e 12, respectivamente, e feitos testes de posicionamento da lâmina e pega neste último. Neste momento, as formas mais detalhadas foram imprescindíveis para notar que a forma circular, inicialmente apontada como um direcionamento para o projeto deveria ser alterada para melhor atender à proposta ergonômica.

Figura 11. Modelos em PU

Fonte: dos autores (permissão de uso)

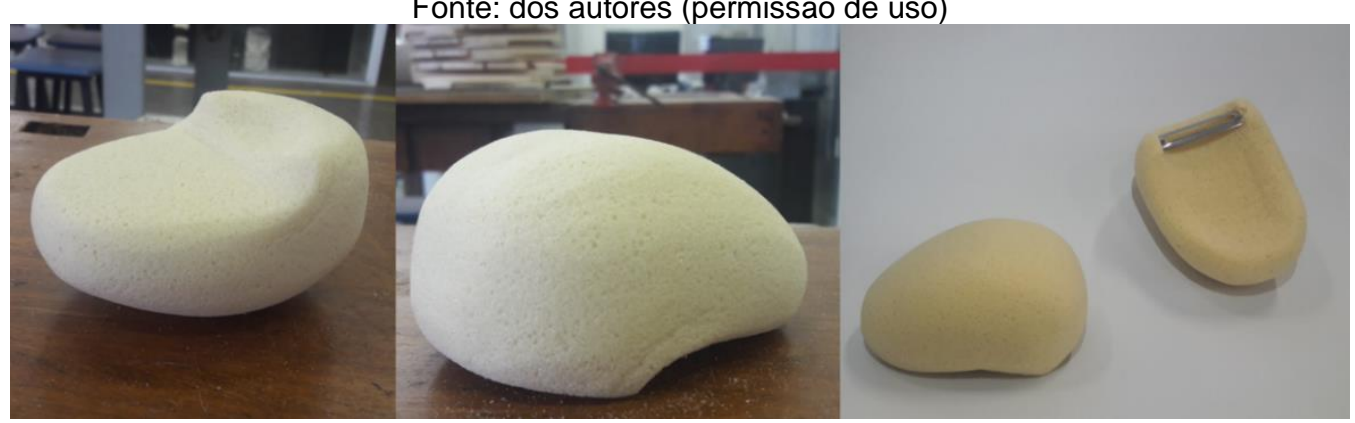

Figura 12: Modelo em argila

Fonte: dos autores (permissão de uso)

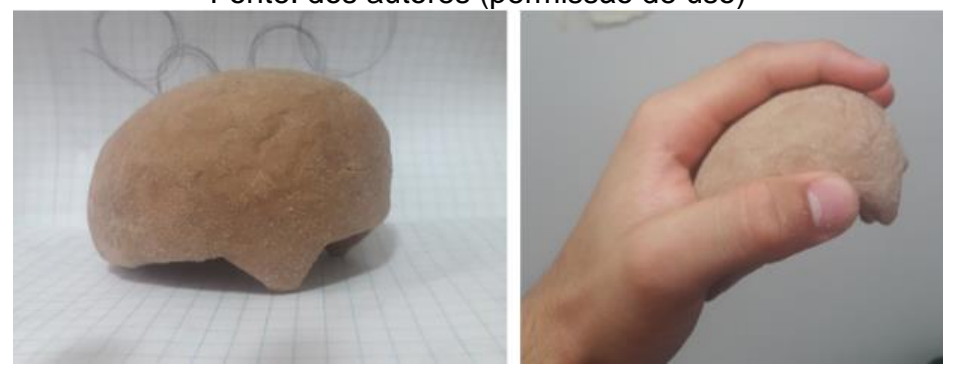

O material selecionado para a prototipação do novo descascador foi a madeira de eucalipto devido sua fácil obtenção, boa resistência, qualidade perceptiva ao produto e também pelo fato da madeira ser um material comum em utensílios de cozinha.

\section{PRODUÇÃO DO PROTÓTIPO}

Feitas as definições quanto a forma e material, partiu-se para o processo de transformação dos materiais e montagem do protótipo físico. A produção do protótipo em madeira foi realizada no Laboratório Didático de Materiais e Protótipos (LDMP) da UNESP Bauru, com processos manuais e técnicas básicas de marcenaria. Foi necessário unir dois pedaços de madeira com cola para formar um bloco e assim realizar a retirada de material até que a forma final fosse atingida (figura 13). 


\section{$17^{\circ}$ ERGODESIGN} \& USIHC 2019

PUC-Rio, 11 a 13 de dezembro Rio de Janeiro, RJ, Brasil $17^{\circ}$ Ergodesign - Congresso Internacional de Ergonomia e Usabilidade de Interfaces Humano Tecnológica: Produto, Informações Ambientes Construídos e Transporte

$17^{\circ}$ USIHC - Congresso Internacional de Ergonomia e Usabilidade

de Interfaces Humano Computador

Figura 13: Colagem das placas de madeira

Fonte: dos autores (permissão de uso)

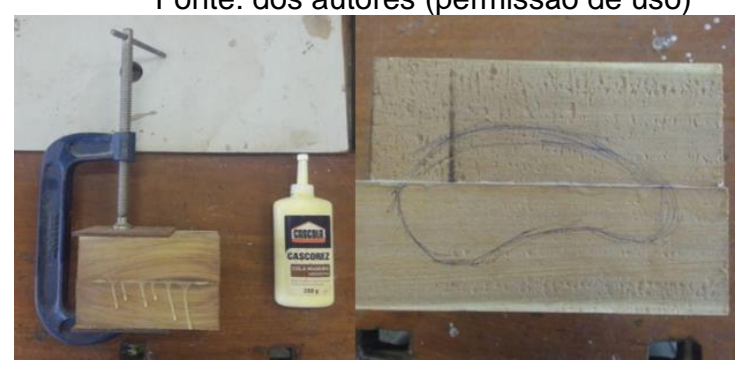

O corte das quinas da peça foi feito com serra de fita e a maior parte do desbaste foi realizado com lixas, tanto com equipamento elétrico (lixadeira circular), quanto os manuais (retífica, grosa e folha de lixa) mostrados nas figuras 14 e 15.

Neste momento, o processo se deu por constantes lixamentos do modelo e verificação da pega. Para atingir a forma final, foi necessárias diversas pequenas correções na forma para garantir que o modelo fosse simétrico, ergonômico e esteticamente agradável.

Figura 14: Recorte e lixamento da forma bruta Fonte: dos autores (permissão de uso)

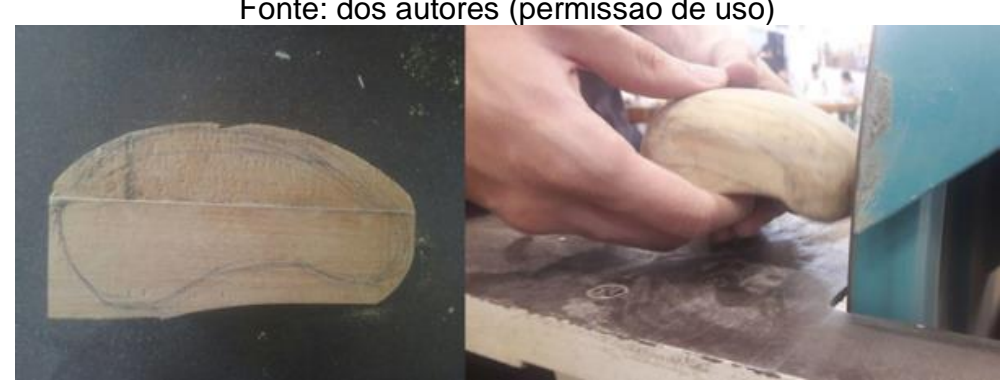

Figura 15: Furação para suporte da lâmina e lixamento Fonte: dos autores (permissão de uso)

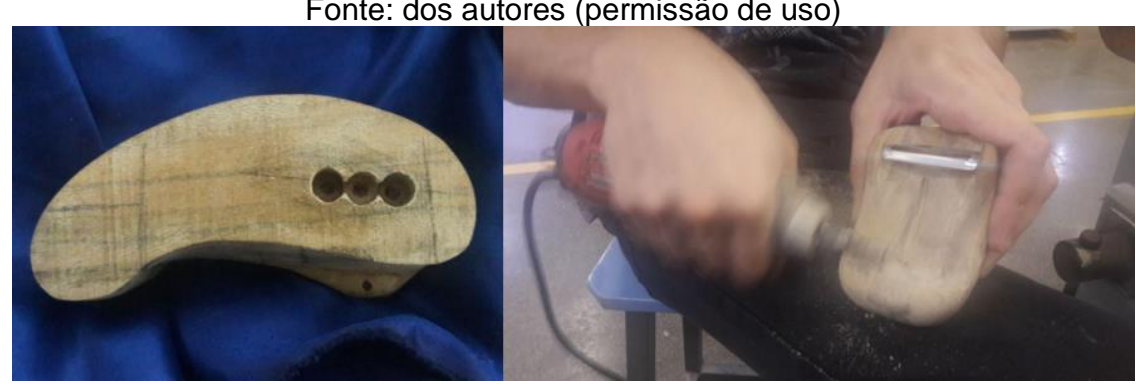

O acabamento foi feito com lixamento com lixas d'água de granulação alta (360 e 400) e aplicação de uma camada de óleo mineral (figura 16) e a lâmina foi retirada de um abridor convencional. 


\section{$17^{\circ}$ ERGODESIGN} \& USIHC 2019

PUC-Rio, 11 a 13 de dezembro Rio de Janeiro, RJ, Brasil $17^{\circ}$ Ergodesign - Congresso Internacional de Ergonomia e Usabilidade de Interfaces Humano Tecnológica: Produto, Informações Ambientes Construídos e Transporte

$17^{\circ}$ USIHC - Congresso Internacional de Ergonomia e Usabilidade

de Interfaces Humano Computador

Figura 16: Aplicação de óleo mineral

Fonte: dos autores (permissão de uso)

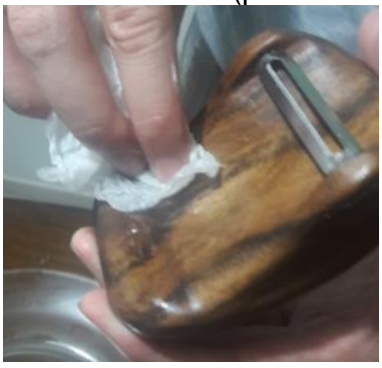

Figura 17: Protótipo finalizado

Fonte: dos autores (permissão de uso)
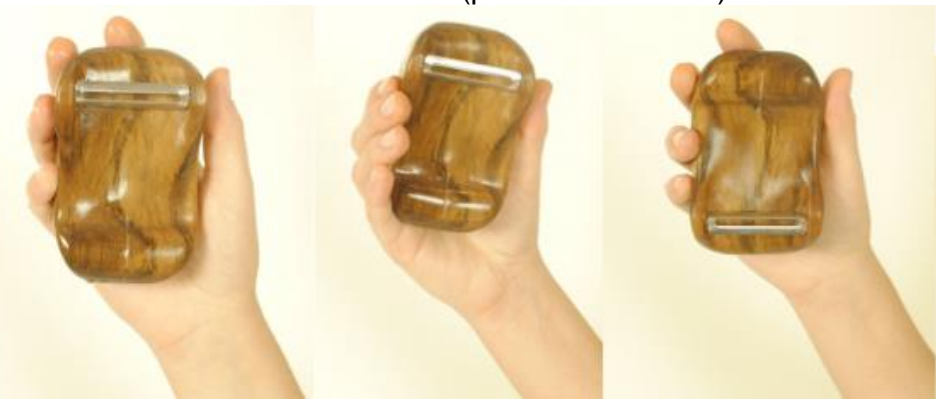

Ao fim do processo de produção do protótipo em madeira, notou-se que o modelo adquiriu certa complexidade de forma e também na sua produção. Além do mais para garantir uma reprodução fidedigna a forma idealizada, o modelo foi digitalizado com scanner $3 d$ (figura 18) para adquirir um modelo virtual que permitisse possíveis reproduções em outros tipos de tecnologia.

O modelo físico foi preparado com marcadores de referência e spray revelador, o qual retira as partes reflexivas e garante um melhor detalhamento da malha gerada, como pode ser visto na figura 19. O modelo virtual foi gerado com o programa GOM inspect e o modelo do equipamento utilizado foi ATOS I da empresa GOM presente no Centro Avançado de Desenvolvimento de Produto (CADEP) situado no campus da UNESP Bauru.

Figura 18: Processo de digitalização

Fonte: dos autores (permissão de uso)

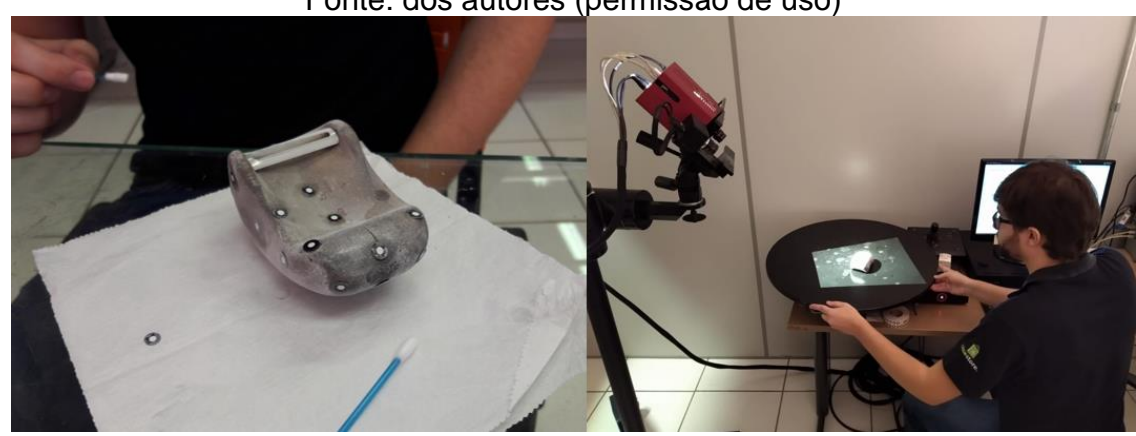




\section{$17^{\circ}$ ERGODESIGN}

\section{\& USIHC 2019}

PUC-Rio, 11 a 13 de dezembro

Rio de Janeiro, RJ, Brasil $17^{\circ}$ Ergodesign - Congresso Internacional de Ergonomia e Usabilidade de Interfaces Humano Tecnológica: Produto, Informações Ambientes Construídos e Transporte

$17^{\circ}$ USIHC - Congresso Internacional de Ergonomia e Usabilidade de Interfaces Humano Computador

Figura 19: Processo de edição e geração do modelo virtual Fonte: dos autores (permissão de uso)

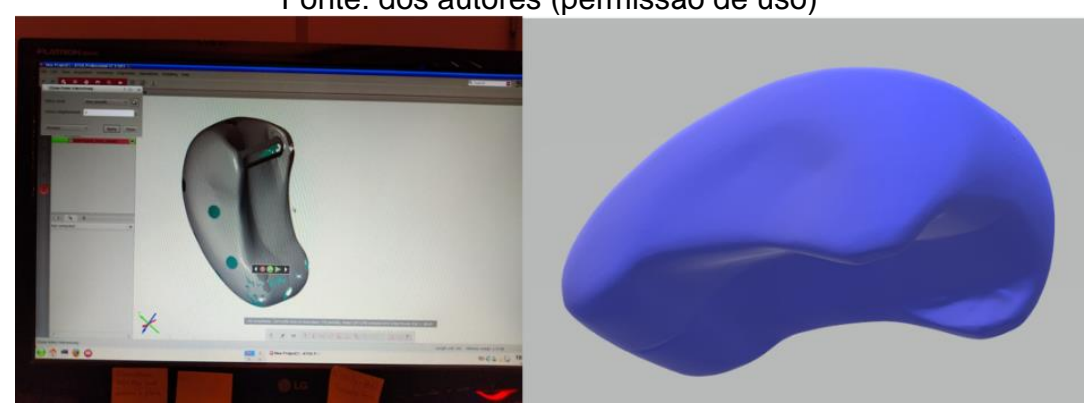

\section{RESULTADOS}

Com o protótipo físico e virtual finalizado, aqui denominado de descascador PETI, foi realizada a aplicação dos testes de ergonomia e usabilidade (DS e SUS) com o modelo em madeira com o objetivo de levantar dados numéricos a serem comparados com os modelos de descascadores comuns previamente testados, e, assim, avaliar o resultado do redesenho do produto.

Figura 20: Processo de edição e geração do modelo virtual Fonte: dos autores (permissão de uso)

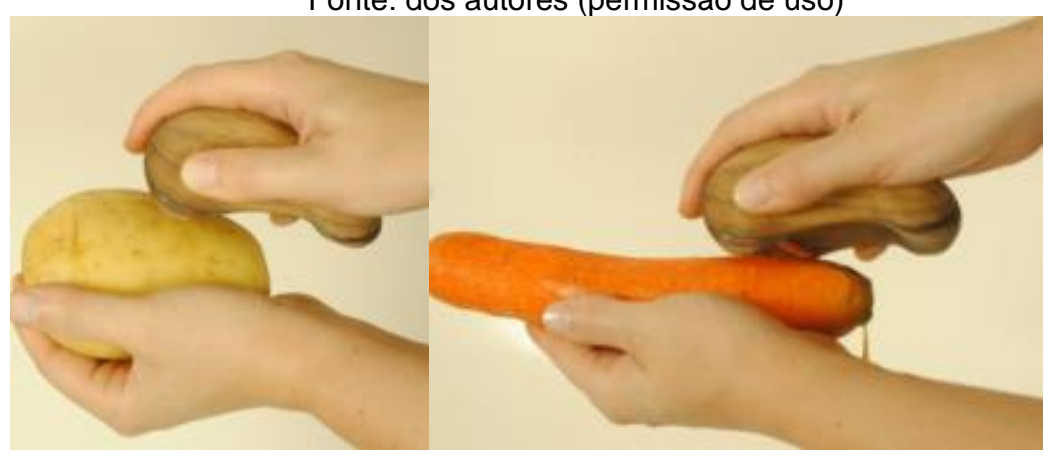

\subsection{Revisão do projeto com base na avaliação dos usuários}

A aplicação dos testes de ergonomia e usabilidade com o protótipo também foram realizadas no LEl e os parâmetros foram idênticos aos do teste realizados com descascadores convencionais. Os testes foram acompanhados pelos docentes e teve como usuários os outros alunos membros das outras equipes das disciplinas. $\mathrm{O}$ objetivo era que cada aluno utilizasse pelo menos três dos protótipos desenvolvidos pelas equipes e que cada protótipo fosse avaliado por 4 alunos e em uma situação de visão total e outra de simulação de cegueira. Os membros da equipe não testaram o próprio protótipo para o levantamento de dados dessa atividade. As etapas de teste foram divididas em: atividade de descascar um pepino com tempo cronometrado e o posterior preenchimento dos questionários SUS e DS. Desta forma, foi possível comparar o desempenho dos três produtos, verificar se as diretrizes de projeto foram contempladas e quais pontos foram melhorados e quais foram piorados.

\subsection{Análise dos resultados}


A figura 20 traz os resultados da análise DS aplicada aos descascadores comercialmente disponíveis, o qual permite destacar que com usuários sem restrição os adjetivos mais indicados foram: "tradicional, funcional e eficiente" para ambos descascadores. Já para usuários com restrição, a indicação foi de maneira diferente, "simples, atrativo e eficiente" foram as mais frequentes. Enquanto que para o protótipo predominou-se "inovador", "seguro" e eficiente", como pode ser visualizado na figura 22 , o que corrobora positivamente com a proposta inicial do projeto de, garantir maior segurança e conforto ao usuário.

Para análise SUS, nota-se que o protótipo apresentou melhor avaliação para ambas situações usuário com restrição e sem restrição.

Figura 21: Resultado Diferencial Semântico descascadores comercialmente disponíveis Fonte: dos autores (permissão de uso)
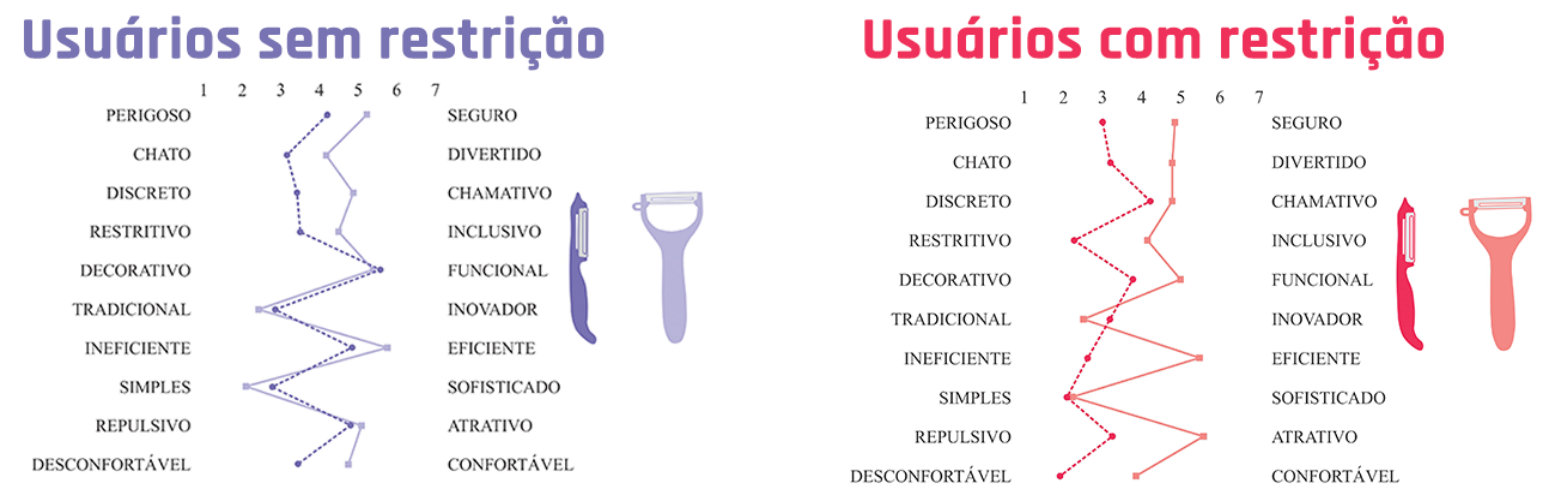

Figura 22. Resultado Diferencial semântico aplicado ao protótipo Fonte: dos autores (permissão de uso)

\section{Usuários com restriçầo}

\section{Usuários sem restriçầo}
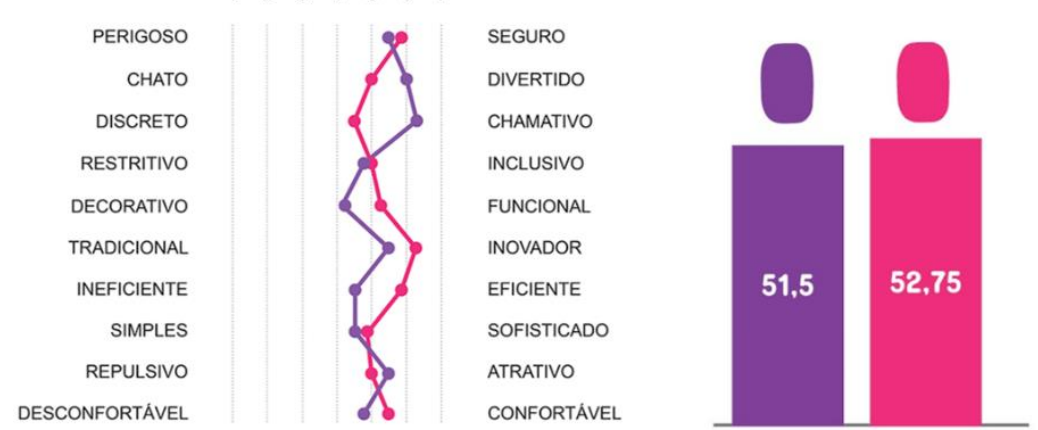
Figura 22: Análise SUS descascadores convencionais e protótipo Fonte: dos autores (permissão de uso)
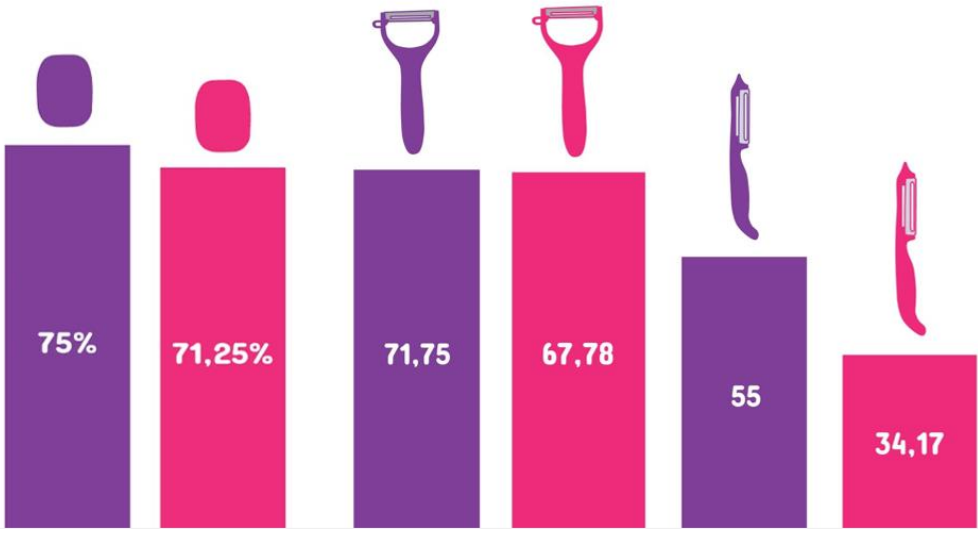

De maneira geral, tanto o teste DS quanto o SUS tiveram resultados superiores aos descascadores comuns, principalmente no que se refere aos usuários cegos. Com média de 52.75 no teste de DS para situação de cegueira, o PETI apresentou diferença considerável em relação aos descascadores disponíveis no mercado. Sendo o do tipo Y apresentando uma média de 43.56 e do tipo Faca com 29.89, nota-se uma diferença de $9.19 \%$ e $22.86 \%$, respectivamente, o que é muito favorável para a avaliação geral do produto, visto que foi possível melhorar o desempenho geral do produto frente a diretriz de inclusão mais satisfatória de usuários com deficiência visual.

\section{CONSIDERAÇÕES FINAIS E CONCLUSÃO}

Os resultados dos testes indicam que o protótipo final atingiu às diretrizes do projeto. $O$ produto desenvolvido obteve bons resultados relacionados a estética e aos requisitos ergonômicos. A interdisciplinaridade permitiu desenvolver as etapas de produção do projeto com melhor embasamento teórico e prático, acima de tudo, o garantiu um ótimo aprendizado relacionado ao desenvolvimento de produtos com design centrado no usuário.

A aplicação de testes de usabilidade permitiu uma melhor compreensão das reais necessidades dos usuários antes da fase de ideação, o que norteou a tomada de decisões mais assertivas durante o desenvolvimento do projeto final. Um aspecto limitante fica por conta do recorte da faixa etária dos usuários testados, sendo composto apenas por jovens adultos, os resultados apresentam certo restringimento em relação a outros grupos que poderiam a ser afetados por dificuldade diferentes das estudadas, tais como idosos, crianças. Contudo, os resultados podem ser considerados expressivos frente a proposta inicialmente apresentada, não apenas no projeto de produto, mas como para o aprendizado para equipe no desenvolvimento de produtos mais ergonômicos e inclusivos.

\section{REFERÊNCIAS BIBLIOGRÁFICAS}

AGNER, Luiz Carlos; MORAES, Anamaria de. Design centrado no usuário e diálogo clientes-organizações através de interfaces na web. Boletim Técnico do Senac, [s.I.], 
v. 28, n. 1, p.24-33, 2018. Disponível em:

<http://bts.senac.br/index.php/bts/article/view/547>. Acesso em: 05 set. 2019.

BONFIM, G.; SILVA, D.; NEVES, E.; PLÁCIDO, J.; MANTOVA, A.; MEDOLA, F. PASCHOARELLI, L. Palmar Pressure and Perception of Discomfort in the Use of Axillary Crutches. Em: Marcelo Soares; Christianne Falcão; Tareq Z. Ahram. (Org.). Advances in Intelligent Systems and Computing. 1ed.: Springer International Publishing, 2017, v. , p. 437449.

CARVALHO, Mayara Vilela de. LESÕES POR ESFORÇOS

REPETITIVOS/DISTÚRBIOS OSTEOMUSCULARES RELACIONADOS AO TRABALHO (LER/DORT): UMA REVISÃO DA LITERATURA. 2018. 27 f. TCC (Graduação) - Curso de Enfermagem, Faculdade Pitágoras, Poços de Caldas, 2018. Disponível em:

<https://repositorio.pgsskroton.com.br/bitstream/123456789/21668/1/MAYARA_VILELA _CARVALHO_ATIVIDADE\%204\%20(2).pdf>. Acesso em: 13 set. 2019.

HOLLOWAY, Z. Ease-e-Peeler. Disponível em: <https://www.behance.net/gallery/31258933/ID2-Ease-e-Peeler> Acesso em 10/12/2017.

IIDA, I. Ergonomia: projeto e produção. 2 ed. São Paulo: Editora Blucher, 2005

MELO, Amanda Meincke. ACESSIBILIDADE E DESIGN UNIVERSAL. In: PUPO, Deise Tallarico; MELO, Amanda Meincke; FERRÉS, Sofia Pérez. ACESSIBILIDADE:

DISCURSO E PRÁTICA NO COTIDIANO DAS BIBLIOTECAS. Campinas:

Unicamp/biblioteca, 2006. p. 17-20. Disponível em:

$<$ http://eurydice.nied.unicamp.br/portais/todosnos/nied/todosnos/artigos-

cientificos/livro_acessibilidade_bibliotecas.pdf.1.pdf\#page=20>. Acesso em: 13 set.

2019.

NORMAN, D. A. O design do dia-a-dia. Rio de Janeiro: Rocco, 2006. 271 p.

PASCOARELLI, L.; COURY, H. Aspectos Ergonômicos e de Usabilidade no Design de Pegas e Empunhaduras. Estudos em Design, Rio de Janeiro, v. 8, n. 1, 2000.

PEREIRA, Juliana; SANTOS, J. Um estudo sobre percepção do usuário e inovação de produto ergonômico em design: apoio plantar de movimentação ava. Revista Convergências, [s.I.], v. 12, n. 23, p.1-6, jun. 2019. Disponível em: <https://repositorio.ipcb.pt/bitstream/10400.11/6569/1/Juliana\%20Pereira\%2c\%20e\%20 outro.pdf>. Acesso em: 10 set. 2019.

TEPPER, R. Potato Peeler. Disponível em : <https://www.behance.net/gallery/24769783/Potato-Peeler> Acesso em 10/12/2017.

\section{AGRADECIMENTOS}

Agradecimentos aos membros do LEl e CADEP pelo apoio na coleta e computação dos dados, 


\section{$17^{\circ}$ ERGODESIGN}

\& USIHC 2019

PUC-Rio, 11 a 13 de dezembro

Rio de Janeiro, RJ, Brasil $17^{\circ}$ Ergodesign - Congresso Internacional de Ergonomia e Usabilidade de Interfaces Humano Tecnológica: Produto, Informações Ambientes Construídos e Transporte

$17^{\circ}$ USIHC - Congresso Internacional de Ergonomia e Usabilidade

de Interfaces Humano Computador

e aos amigos de equipe Gabriela Luciana Braz, Mateus Giacomine, Thamires Bueno e Estella Torres no desenvolvimento do projeto. 